\title{
Prioritizing teacher emotions: shifting teacher training to a digital environment
}

\author{
Julie K. Owens ${ }^{1}$ (D) . Alida K. Hudson ${ }^{1}$ \\ Accepted: 21 November 2020 / Published online: 14 January 2021 \\ (c) Association for Educational Communications and Technology 2021
}

\begin{abstract}
This paper is in response to the manuscript entitled, "Success, failure and emotions: Examining the relationship between performance feedback and emotions in diagnostic reasoning," (Jarrell, Harley, Lajoie, \& Naismith, Educational Technology \& Research Development, 65, 1263-1284: 2017) from a K-12 teacher and administrator educational perspective. Jarrell et al.'s (Educational Technology \& Research Development, 65, 12631284: 2017) findings indicate a strong relationship between outcome emotions and performance tasks: highest performing medical students had the most positive emotions. The authors suggested that medical students who fail and experience negative emotions could experience a loss of confidence and lead to dropping out of medical school. These results can be applied to teachers and administrators in K-12 settings as they make the shift to digital learning by including emotional assessments into the new digital learning platforms in order to address areas of emotional stress and teacher burnout before leading to attrition. This perspective makes suggestions of ways Jarrell et al.'s (Educational Technology \& Research Development, 65, 1263-1284: 2017) findings could be a starting place for educational stakeholders to prioritize teachers' emotional well-being and offer an opportunity to provide intervention support in order to increase teacher self-efficacy in the shift to digital and possibly reduce teacher burnout.
\end{abstract}

Keywords Performance feedback · Teacher emotions · Teacher burn-out

In their 2017 paper, Jarrell \& colleagues extend prior research on the relationship between outcome emotions and classroom performance to a computer-based learning environment (CBLE). In this study, 30 medical students completed three case studies of varying difficulty (i.e., easy, moderate, and difficult) in which they evaluated a patient's medical history, proposed a diagnosis supported by evidence, justified their decisions, and reported their level of confidence in the proposed diagnosis. After each case study, students received personalized feedback on both the efficiency and accuracy of their diagnosis. Students

Julie K. Owens

juliekateowens@tamu.edu

Alida K. Hudson

alida.hudson@tamu.edu

1 Texas A\&M University, College Station, TX, USA 
then responded to 25 Likert scale items designed to capture the emotions they experienced after receiving feedback on their performance in the CBLE. Findings mirrored previous research in that a strong relationship between outcome emotions and performance tasks in the CBLE was found, with the highest performing participants having the most positive emotions. Further, Jarrell and colleagues posit that it is both emotional valence, one's intrinsic attractiveness or averseness to a situation, and intensity, one's subjective value of the activity, that work together to influence performance outcomes.

Jarrell et al.'s (2017) findings, along with previous studies on the relationship between emotions and performance, are of great importance and extend to all areas of teaching and learning. As Pekrun and Perry (2014) highlight, one's disposition to future learning and task engagement can be strongly influenced by one's emotions. Experiencing success accompanied with positive feedback may lead to feelings of joy, pride, and confidence. Whereas, failure and negative feedback, especially when experienced over and over again, may instill feelings of anger, shame, and disappointment within the learner, thus leading to hopelessness and task avoidance.

While the relationship between student's emotions and performance outcomes are wellsupported in the research, the association between teachers' or administrators' emotions and performance is less prevalent. Teaching is a job of high demands and low control, which often leads to emotional exhaustion, increases in teacher turnover, and a decrease in teaching performance (Shackleton et al. 2019). Utilizing emotional assessments within professional development (PD) in CBLEs could provide early identification of teacher stress and provide educational stakeholders with a place to begin addressing the stress before it results in teacher attrition.

Just as Jarrell et al. (2017) highlighted that a medical student who fails to correctly diagnose a patient may lose confidence in their abilities and drop out of medical school, classroom teachers may lose confidence in their abilities to teach after failing to meet the needs of a student performing below grade level or struggling to effectively manage student behavior within the classroom. These negative experiences, which may be accompanied by adverse feedback from administration, may lead teachers to potentially decide to leave the teaching profession altogether. For example, Holme et al. (2018) found that teachers leave schools with low-performing students at a much higher rate than teachers with the highestperforming students (i.e., $31.4 \%$ for the lowest performing schools, $16.8 \%$ for the highest performing schools. In the lowest performing schools, teachers are often required to devote more time, both during and outside of the normal school hours, to attend trainings and meetings aimed at increasing student performance. Thus, one cannot help but wonder how the emotions of the teachers and the feedback they receive from district and campus administration play into their decisions to leave, especially since teachers report that they do not leave schools because of the students but rather because of the poor work environment (Simon and Johnson 2015).

Recently, the COVID-19 global pandemic has forced all teachers and administrators to adapt and engage in a digital learning environment. In the traditional face to face learning environment, administrators, teachers, and students are able to utilize facial expressions, body language, intonations, and other emotional cues to communicate their social, emotional, and learning needs, but those tools of communication may not be as readily available in a virtual learning setting. Teachers are now being inundated with online, computerbased PD in order to learn how to effectively provide engaging, authentic virtual learning experiences for students while also navigating isolation during a global pandemic. Jarrell et al.'s (2017) findings highlight that administrators and district leaders must also consider the teachers' emotional state and perceived value of the new digital learning. Thus, 
incorporating emotional assessments within virtual PD, or CBLEs, may help to address the varying needs of K-12 classroom educators in a virtual environment. The change from face-face instruction to virtual learning removes a level of intimacy and connectedness among school colleagues. Thus, administrators could use feedback from teachers' emotional responses within a virtual learning setting to identify educators who may be in need of emotional support. Consequently, administrators could plan for an appropriate intervention, such as addressing the underlying poor performance on a given task or discussions to regulate the experience of negative emotions which may potentially lead to the educator leaving the professional altogether.

This study presents a good exploration of causal relationships between emotions and diagnostic outcomes. Future research will need to establish causal relationships between interventions about emotions and how they affect outcomes. Further, it will be an interesting research agenda to focus on whether these emotional factors are malleable. Just as early identification and intervention for learning difficulties is critical for student success, identifying teachers (and administrators) in need of emotional support early on may be a deciding factor in reducing teacher attrition during the current shift to a digital learning environment. In the shift to a digital environment, virtual PD, or CBLEs, for teachers could begin including emotional assessments, such as a self-report questionnaire or Likert-scale items, throughout the training process. Further, CBLEs for educators could provide feedback responses (Feidakis et al. 2014) that both validate teachers' feelings and also provide tools for self-regulation based on the teacher's specific outcome emotions. Now more than ever, if we are to retain our nation's educators, the emotions of our educational professionals need to be recognized and supported, thereby creating a positive school environment in which all students, teachers, and administrators can thrive.

\section{Compliance and ethical standards}

Conflict of interest These authors declare no potential conflicts of interest.

\section{References}

Feidakis, M., Daradoumis, T., Caballe, S., \& Conesa, J. (2014). Embedding emotion awareness into e-learning environments. International Journal of Emerging Technologies in Learning., 9(7), 39-46. http:// onlinejournals.org/index.php/i-jet/author/downloadFile/3727/12009/1.

Holme, J. J., Jabbar, H., Germain, E., \& Dinning, J. (2018). Rethinking teacher turnover: Longitudinal measures of instability in schools. Educational Researcher, 47(1), 62-75. https://doi.org/10.3102/00131 89X17735813.

Jarrell, A., Harley, J. M., Lajoie, S., \& Naismith, L. (2017). Success, failure and emotions: Examining the relationship between performance feedback and emotions in diagnostic reasoning. Educational Technology \& Research Development, 65, 1263-1284. https://doi.org/10.1007/s11423-017-9521-6.

Pekrun, R., \& Perry, R. P. (2014). Control-value theory of achievement emotions. In R. Pekrun \& L. Linnenbrink-Garcia (Eds.), Educational psychology handbook series. International handbook of emotions in education (pp. 120-141). London: Routledge/Taylor \& Francis Group.

Shackleton, N., Bonell, C., Jamal, F., Allen, E., Mathiot, A., Elbourne, D., \& Viner, R. (2019). Teacher burnout and contextual and compositional elements of school environment. Journal of School Health, 89(12), 977-993. https://doi.org/10.1111/josh.12839.

Simon, N. S., \& Johnson, S. M. (2015). Teacher turnover in high-poverty schools: What we know and can do. Teachers College Record, 117(3), 1-36. 
Publisher's Note Springer Nature remains neutral with regard to jurisdictional claims in published maps and institutional affiliations.

Julie K. Owens is a doctoral candidate in the department of Teaching, Learning, and Culture at Texas A\&M University-College Station, College Station, TX, USA; Julie's research interests include implementation science, Self-Regulated Strategy Development in writing instruction, and principal-teacher relationships.

Alida K. Hudson is a Ph.D. student in Curriculum \& Instruction with an emphasis in Reading and Literacy at Texas A\&M University-College Station, College Station, TX, USA; Alida serves as the Chair of the Texas Association for Literacy Education, the Texas affiliate of the International Literacy Association (ILA). Alida was recently awarded the 2019 Jack Cassidy Award for Scholarly contributions from the Standardized Literacy Professionals Special Interest Group of ILA. 